\begin{abstract}
The spatial distributions of the valence-electron density and the total energy reliefs for water (or methanol) migration on the free surface of graphene are obtained, by using the electron density functional and ab initio pseudopotential methods. Water and methanol molecules are found to migrate along the surface of graphene with an energy relief with barriers and wells. The interaction of water molecules located on the opposite sides of the graphene plane through the regions in the graphene plane with a low electron density is detected. The hovering of molecule over the graphene plane is found to locally change plane's conductivity. The estimate of energy costs during the propagation of adsorbent molecules over the graphene surface testifies to the graphene hydrophobicity.
\end{abstract}

Keywords: electron density functional method, pseudopotential method, graphene, water, methanol.

\section{Introduction and Statement of the Problem}

Graphene is a two-dimensional allotropic modification of carbon formed by a monolayer of $s p 2$-hybridized carbon atoms that are bound by $\sigma$-and $\pi$-bonds into a hexagonal two-dimensional crystal lattice possessing a unique combination of properties. Despite the intense studies of graphene, there are few reports containing the information on the interaction between water (methanol) and graphene, which could be important for using graphene in protective coatings [1-7]. The information concerning the wetting of graphene by water and methanol can promote the development of various applications. In particular, hydrophobic and superhydrophobic surfaces have a low surface energy and, as a rule, are electric insulators. A conformal coating of such surfaces with graphene can result in the creation of a new class of conducting superhydrophobic surfaces, which can be applied in various domains [8-11]. Bearing all that in mind, we calculated the energy barriers for water and methanol migration along the graphene plane in the framework of the electron density functional and $a b$ initio pseudopotential methods. All calculations were carried out with the help of our own program code [12].

(c) A.G. BARYLKA, R.M. BALABAI, 2015

ISSN 2071-0194. Ukr. J. Phys. 2015. Vol. 60, No. 10

\section{Models and Calculation Methods}

All our estimates of static structural properties in terms of the energy evolution are based on the following assumptions: (i) electrons are in the ground state for every instant positions of nuclei (the Born-Oppenheimer adiabatic approximation); (ii) many-particle effects are estimated in the framework of the local electron density functional formalism, and (iii) the socalled frozen core approximation, i.e. pseudopotentials, is used. The theory of pseudopotentials makes it possible to use the convenient mathematical apparatus of Fourier transformations, because, owing to the pseudopotential weakness, plane waves can be used as the basis functions at expanding one-particle electron wave functions. Due to the artificial symmetry of examined objects, the expression for the total energy can be written simpler in the momentum space. The total energy per unit cell looks like

$$
\begin{aligned}
& E_{\mathrm{tot}} / \Omega=\sum_{k, G, i}\left|\Psi_{i}(\mathbf{k}+\mathbf{G})\right|^{2} \frac{\hbar^{2}}{2 m}(\mathbf{k}+\mathbf{G})^{2}+ \\
& +\frac{1}{2} 4 \pi e^{2} \sum_{G}^{\prime} \frac{|\rho(\mathbf{G})|^{2}}{\mathbf{G}^{2}}+\sum_{G} \varepsilon_{x c}(\mathbf{G}) \rho^{*}(\mathbf{G})+ \\
& +\sum_{G, \tau}^{\prime} S_{\tau}(\mathbf{G}) V_{\tau}^{L}(\mathbf{G}) \rho^{*}(\mathbf{G})+\sum_{k, G, G^{\prime}, i, l, \tau} S_{\tau}\left(\mathbf{G}-\mathbf{G}^{\prime}\right) \times \\
& \times \Delta V_{l, \tau}^{N L}\left(\mathbf{k}+\mathbf{G}, \mathbf{k}+\mathbf{G}^{\prime}\right) \Psi_{i}(\mathbf{k}+\mathbf{G}) \Psi_{i}^{*}\left(\mathbf{k}+\mathbf{G}^{\prime}\right)+
\end{aligned}
$$




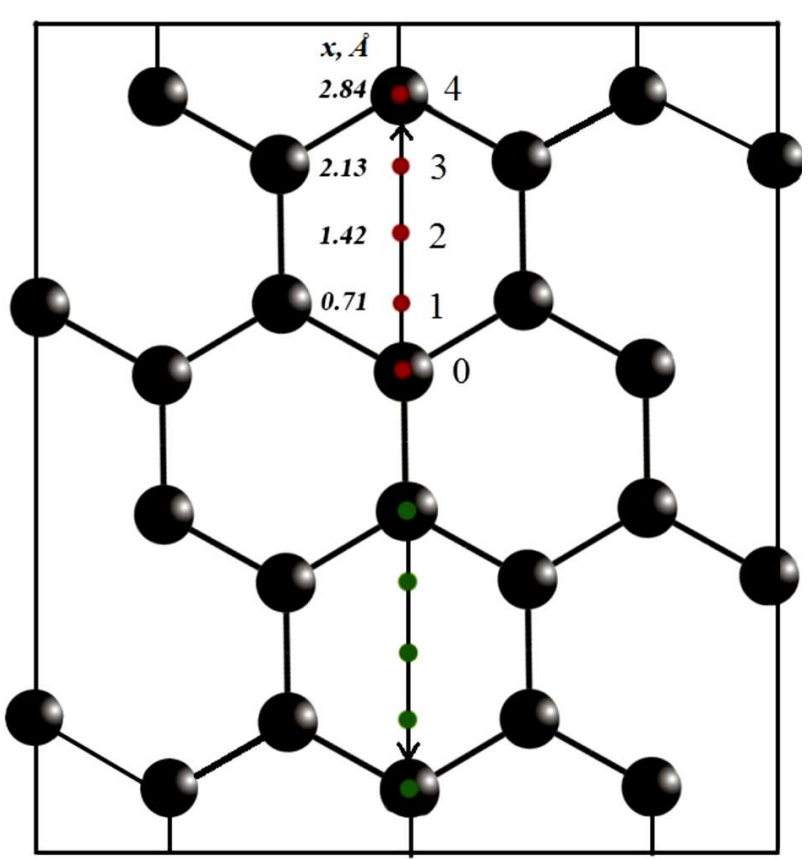

Fig. 1. Schematic diagram of the water (or methanol) molecule migration on the graphene plane

$+\left\{\sum_{\tau} \alpha_{\tau}\right\}\left[\Omega^{-1} \sum_{\tau} Z_{\tau}\right]+\Omega^{-1} \gamma_{\text {Ewald }}$

where the vector $\mathbf{k}$ belongs to the first Brillouin zone, $\mathbf{G}$ is the reciprocal lattice vector, $\Psi_{i}(\mathbf{k}+\mathbf{G})$ is the wave function, the subscript $i$ marks occupied states for a definite $\mathbf{k}, \rho(\mathbf{G})$ is the coefficient in the expansion series of the valence-electron density, the primed sum sign means that the term corresponding to $\mathbf{G}=0$ is absent, the subscript $\tau$ enumerates atoms in the unit cell, $S_{\tau}(\mathbf{G})$ is the structural factor, $V_{\tau}^{L}$ is a local spherically symmetric pseudo-potential independent of the quantum orbital number $l, \Delta V_{l, \tau}^{N L}$ is the nonlocal correction to $V_{\tau}^{L}$ dependent on $l, Z_{\tau}$ is the ion charge, and $\gamma_{\text {Ewald }}$ is the Madelung energy of pointlike ions in a uniform negative background.

The coefficients in the Fourier series of the electron charge density are calculated by the formula

$\rho(\mathbf{G})=\sum_{i} \sum_{\mathbf{G}^{\prime}, \alpha} \Psi_{i}(\mathbf{k}+\mathbf{G}) \Psi_{i}^{*}\left(\mathbf{k}+\alpha \mathbf{G}^{\prime}\right)$

where $\Psi_{i}(\mathbf{k}+\mathbf{G})$ are the coefficients of the expansion in plane waves of the one-particle wave function, which can be obtained from band-structural calcula- tions, and $\alpha$ is the operator of symmetric transformations from the point symmetry group for the unit cell.

In order to calculate the exchange and correlation energies per electron, $\varepsilon_{x c}$, we used the Ceperley-Alder approximation parametrized by Perdew and Zunge. The integration over $\mathbf{k}$ was substituted by calculation at $\Gamma$-point.

The capability of graphene to be wetted by water or methanol was estimated from the energy expenses needed for the adsorbent molecules to propagate over the surface. The calculation procedure was as follows. First, the adsorption bond length was determined, i.e. the distance between water (methanol) molecules at their migration was chosen. The choice was associated with the fact that the minimum distance between a water molecule and the graphene plane should be equal to the sum of the Bohr radii of the largest atom in the water molecule and the carbon atom. The maximum distance of the molecule from the graphene plane was determined by the disappearance of the electron density exchange between the molecule and graphene. Then, the following scenario of surface diffusion was used. Within a diffusion step between two surface positions, the adsorption bond length was assumed to remain invariable. The direction of molecule migration was selected along the hexagon diagonal (the direction [1100]). Then the initial positions of molecules with respect to carbon atoms in graphene and the displacement step were chosen. A trajectory of the described migration is shown in Fig. 1. The total energy was calculated for every atomic configuration corresponding to the elementary step of surface diffusion, thus generating the energy relief along the migration trajectory of a water (or methanol) molecule.

Since the calculation algorithm was developed, by assuming the translational symmetry of the researched atomic system, a supercell of tetragonal type was created first of all. Its parameters and atomic basis depended on the research object. The atomic basis of a primitive cell in the artificial lattice reproducing the graphene plane covered with water molecules from both sides included 30 atoms; and 36 atoms in the case of the plane covered with methanol molecules. The account of the translational symmetry was equivalent to the consideration of an infinite graphene plane covered with water (or methanol) molecules at a concentration of $8.3 \%$.

ISSN 2071-0194. Ukr. J. Phys. 2015. Vol. 60, No. 10 


\section{Results of Calculations and Their Discussion}

With the help of our own program code [12], we calculated the total energies of the model atomic system and the spatial distributions of the valence-electron density. In addition, the cross-sections of those spatial distributions were determined for the $\Gamma$-point in the Brillouin zone of the 3D superlattice.

In Fig. 1, a schematic diagram of water (or methanol) molecule migration along the graphene plane is shown. The direction of water (or methanol) motion is designated by an arrow, the points mark the positions of molecules, at which the energy of the studied object was calculated. Top and bottom points mark the positions of molecules that move on different sides of the graphene plane. Figure 1 also demonstrates the atomic basis of the primitive cell in the artificial lattice. The water molecule is oriented by its oxygen atom toward the graphene plane.

Figures 2 to 4 illustrate variations of the total energy of the graphene plane during the migration (surface diffusion) of water (or methanol) molecules along it. The molecules are separated from the graphene plane by distances, which are probable for the surface diffusion processes. It should be noted that the migration of molecules occurs simultaneously on the both sides of graphene plane. The model trajectory (see Fig. 1) contains a point (this is position 0, at which the molecule is located above the carbon atom), when the molecules are the closest to each other. At the same time, molecules at position 2 (the atomic hexagon center in the graphene plane) are the most distant from each other.

Figures 2 and 3, which demonstrate the potential reliefs for water molecules that migrate in the same direction along the graphene plane, but at different distances from it, reveal strong quantitative differences. In particular, when water molecules migrate at a short distance from the both sides (lower and upper) of graphene plane and, so to say, feel each other, the model atomic system has the highest energy, when the water molecule is located at the hexagon center (the potential relief has a barrier at this point). When water molecules are located in vicinities of carbon atoms, which screen their interaction, the energy of the atomic configuration decreases. In other words, water molecules, when approaching the hexagon vertices, turn out in an energy well. The energy differ-
$\mathbf{E}$

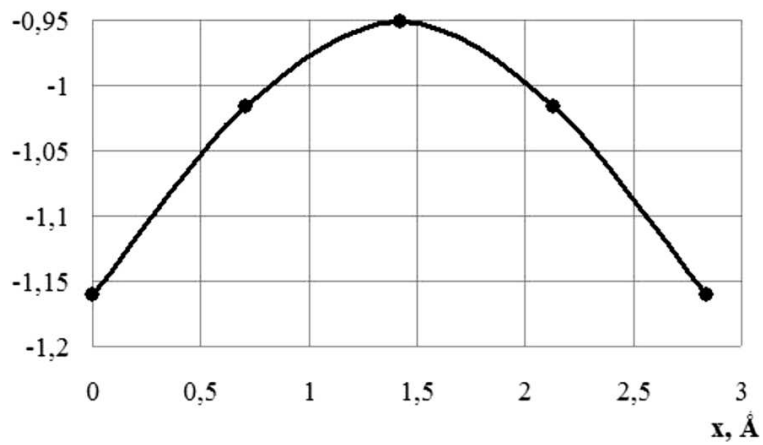

Fig. 2. The potential relief for a water molecule in the direction [1100] along the graphene surface. The distance between the water molecule and graphene equals $1.9 \AA$. The energy is reckoned in atomic unities per atom, and the distance in angströms

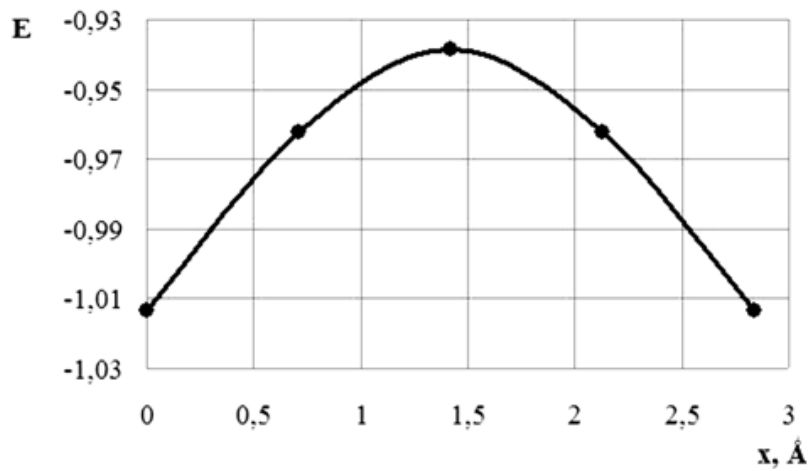

Fig. 3. The same as in Fig. 2, but for the distance between the water molecule and the graphene plane equal to $2.9 \AA$

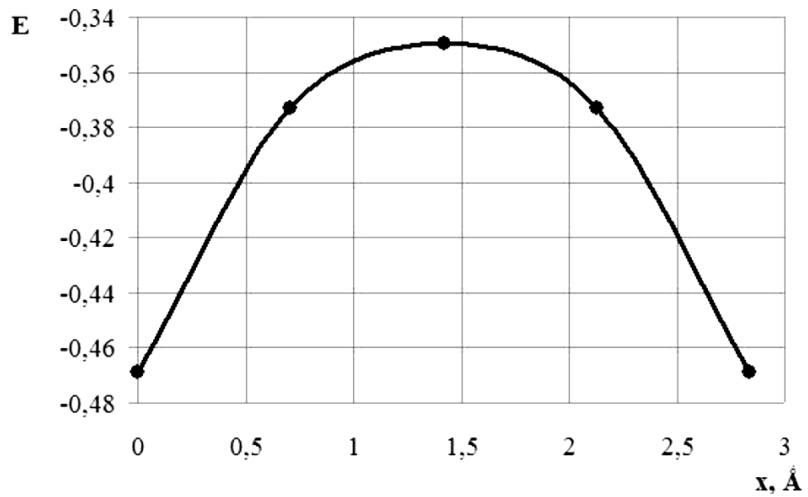

Fig. 4. The same as in Fig. 2, but for the distance between the water molecule and the graphene plane equal to $3 \AA$

ence between the maximum and the minimum of the potential relief amounts to 0.21 a.u. per atom. When water molecules migrate at a long distance from the both sides (lower and upper) of the graphene plane 


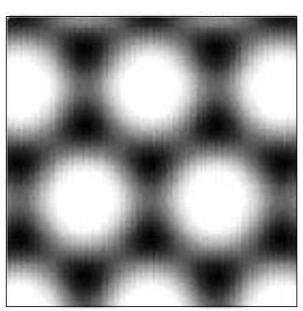

$a$

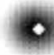

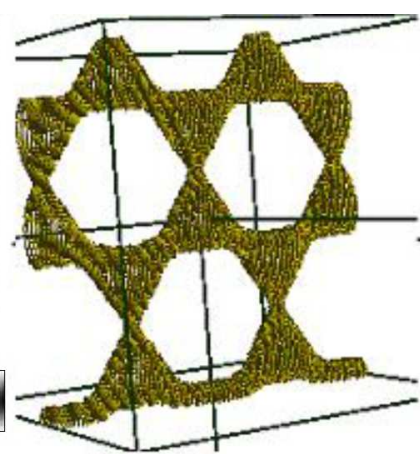

$c$

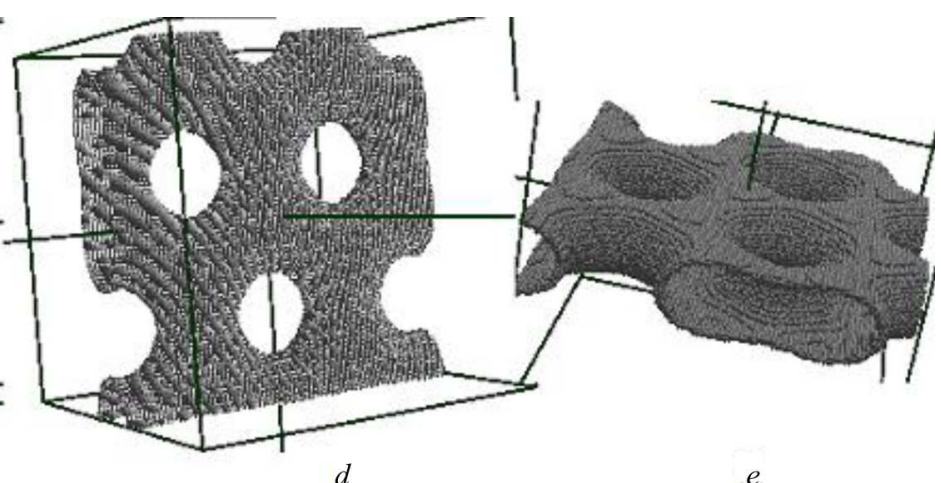

$d$

Fig. 5. Distributions of the valence-electron density near an unconfined graphene plane: longitudinal $(a)$ and transverse (b) cross-sections of spatial distribution through the centers of atoms. Spatial distributions of the valence-electron density for isovalues of $0.6-0.7(c)$ and $0.1-0.2(d$ and $e$, at different aspect angles) times the maximum value

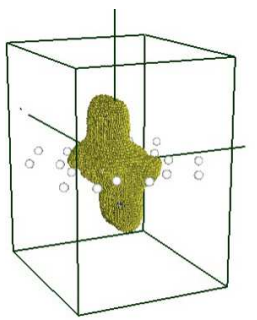

0

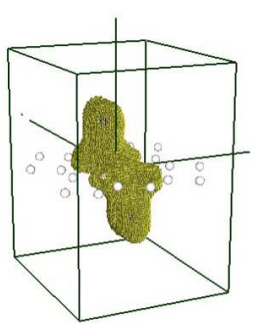

1

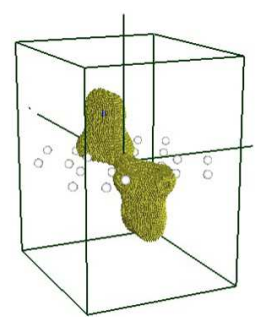

2
Fig. 6. Spatial distributions of the valence-electron density near a graphene film covered with migrating water molecules for isovalues of $0.4-0.5$ times the maximum. Molecules are at a distance of $1.9 \AA$ from the graphene plane and move along the direction [1100]. The numbers of panels correspond to the numbers of positions in Fig. 1

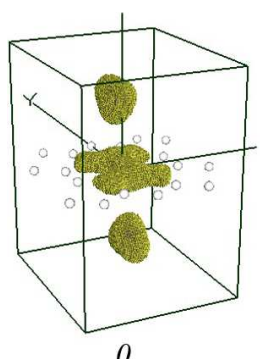

0

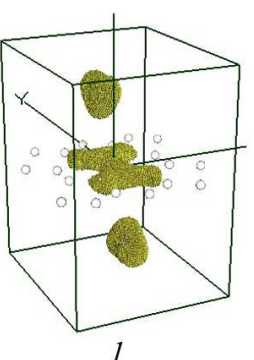

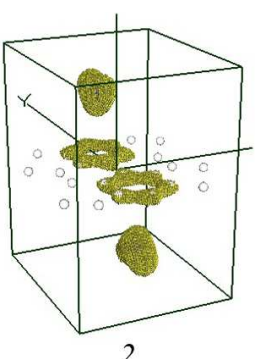

2
Fig. 7. The same as in Fig. 6, but for the distance between the water molecule and the graphene plane equal to $2.9 \AA$

and do not feel each other, the energy profile of migration has the same character. But the energy difference between the maximum and the minimum of the potential relief amounts to only 0.07 a.u. per atom. Hence, the height of the energy barrier for the migration of water molecules on the graphene surface diminished by $66 \%$.
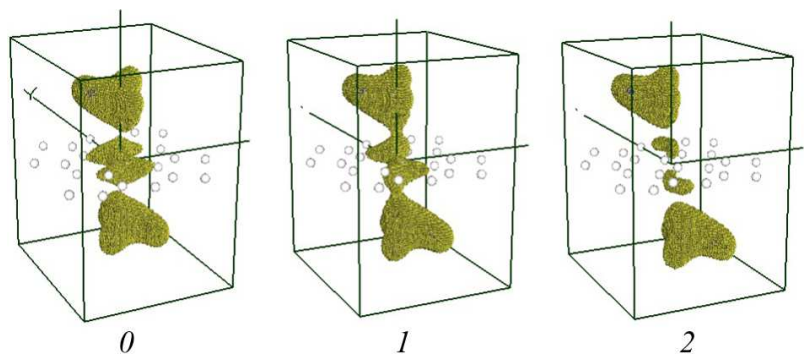

Fig. 8. The same as in Fig. 6, but for the distance between the water molecule and the graphene plane equal to $3 \AA$

Attention should be paid to a feature in the electron density distribution in the case of a free unconfined graphene plane. At the centers of atomic hexagons, the own electron density of graphene equals zero (Fig. 5). This natural vacuum "hole" in the graphene plane creates a channel, through which water molecules located on the different sides of the graphene plane can interact. The reality of this interaction is confirmed by spatial distributions of the electron density and their cross-sections depicted in Figs. 6-11. Figures 6-8 illustrate variations in the spatial distribution of the valence-electron density that accompany the migration of water (or methanol) molecules along the graphene surface in the direction [1100], with the molecules being at certain distances from the graphene plane that are probable for the surface diffusion processes. Figures 9-11 demonstrate the cross-sections of those distributions in mutually perpendicular planes.

Concerning the migration of methanol molecules at a long distance from the graphene plane $(3 \AA)$, the corresponding energy barrier height amounts to

ISSN 2071-0194. Ukr. J. Phys. 2015. Vol. 60, No. 10 

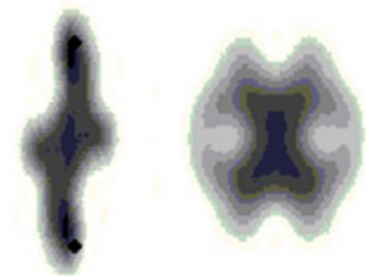

0
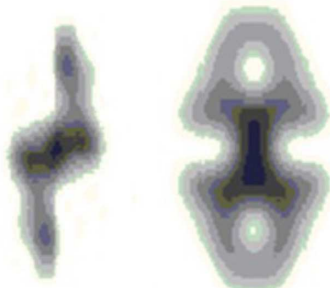

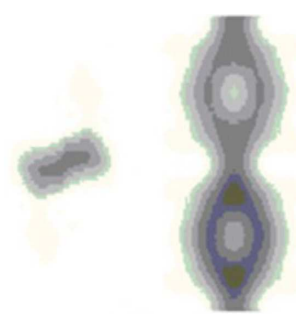

2

Fig. 9. Mutually perpendicular cross-sections of the valence-electron density near the graphene plane at various positions of a water molecule on the migration trajectory. The molecule is at a distance of $1.9 \AA$ from the graphene plane. The numbers of panels correspond to the numbers of positions in Fig. 1

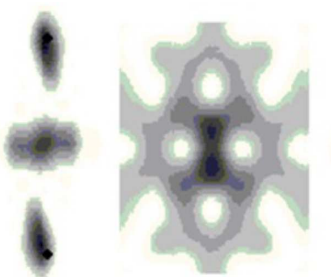

0

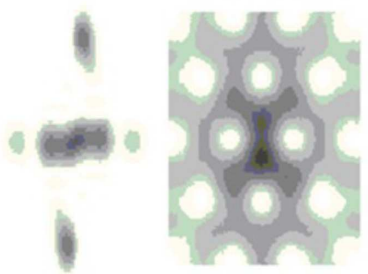

1

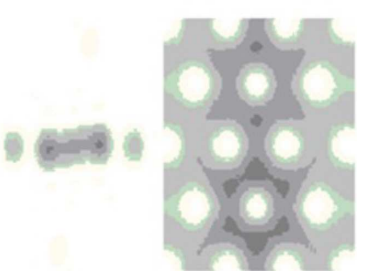

Fig. 10. The same as in Fig. 9, but for the distance between the water molecule and the graphene plane equal to $2.9 \AA$
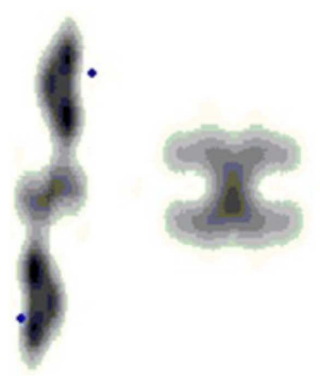
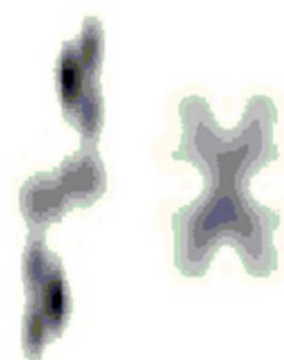

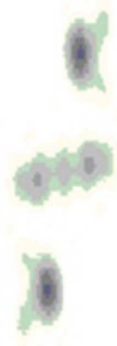

Fig. 11. The same as in Fig. 9, but for the distance between the water molecule and the graphene plane equal to $3 \AA$

0.13 a.u., which is by $50 \%$ larger than in the case of water molecules that move at the same distance.

Elementary atomic processes running on the graphene surface during its wetting by water or alcohol are governed by interactions between adsorbent molecules and the surface. An exchange of the electron charge was registered between migrating molecules and the nearest graphene atoms, with the exchange intensity depending on the position of the adsorbed molecule on the surface (see Fig. 6). Another situation was also observed when the valence-electron bridges in the vacuum gap between the molecules and the graphene plane were absent, but molecule's "shadow" with a higher electron density appeared on the plane under the real molecule (see Fig. 7). In other words, the hovering of a molecule above the graphene plane locally changed its conductivity.

\section{Conclusions}

Using the electron density functional and $a b$ initio pseudo-potential methods, the distributions of the valence-electron density and the total energy reliefs for the water migration on the free graphene surface 
are calculated. Water or methanol molecules migrate over the graphene surface, which is characterized by an energy relief with barriers (at the centers of atomic hexagons in the graphene plane) and wells (in vicinities of carbon atoms). The barrier height depends on the distances between the molecules and the graphene plane. Interaction through regions with a low electron density in the graphene plane is registered between water molecules located on the different sides of the plane. The hovering of molecules over the graphene plane is found to locally change plane's conductivity. The estimation of energy costs during the propagation of adsorbent molecules on the graphene surface testifies to the phobicity of graphene with respect to water and alcohol, which is a result of the nonuniform character of the energy barrier.

1. J. Rafiee, Xi Mi, H. Gullapalli, A.V. Thomas, F. Yavari, Y.Shi, P.M. Ajayan, and N.A. Koratkar, Nature Mater. 11, 217 (2012).

2. Chih-Jen Shih, Qing Hua Wang, Shangchao Lin, KyooChul Park, Zhong Jin, M.S. Strano, and D. Blankschtein, Phys. Rev. Lett. 109, 176101 (2012).

3. R.R. Nair, P. Blake, A.N. Grigorenko, K.S. Novoselov, T.J. Booth, T. Stauber, N.M.R. Peres, and A.K. Geim, Science 320, 1308 (2008).

4. F. Yavari et al., Small 6, 2535 (2010).

5. J. Rafiee, M.A. Rafiee, Z.Z. Yu, and N. Koratkar, Adv. Mater. 22, 215 (2010).
6. S. Barzilai, N. Froumin, E. Glickman, D. Fuks, and N. Frage, J. Mater. Sci. 47, 8404 (2012).

7. Quanzu Yuan and Ya-Pu Zhao, J. Fluid Mech. 716, 171 (2013).

8. M. Sansotera et al., Carbon 48, 4382 (2010).

9. J.T. Han, S.Y. Kim, J.S. Woo, and G.W. Lee, Adv. Mater. 20, 3724 (2008).

10. J. Zou et al., Adv. Mater. 20, 3337 (2008).

11. T. Darmanin and F. Guittard, J. Am. Chem. Soc. 131,7928 (2009).

12. R.M. Balabai, Ukr. J. Phys. 58, 389 (2013).

Received 19.10.14.

Translated from Ukrainian by O.I. Voitenko

\section{А.Г.Барилка, Р.М. Балабай}

ЗМОЧУВАННЯ ГРАФЕНУ МЕТАНОЛОМ АБО ВОДОЮ

$\mathrm{P}$ е $з$ ю м е

Методами функціонала електронної густини та псевдопотенціалу із перших принципів отримано розподіли густини валентних електронів та повні енергії для міграції води (або метанолу) на вільній поверхні графену. Було встановлено, що міграція молекул води та метанолу уздовж поверхні графену відбувається з енергетичним рельєфом, котрому притаманні бар'єри та ями. Зафіксована взаємодія молекул води, що знаходяться по різні боки від площини графену, через області малої ймовірності в розподілі електронної густини графенової площини. Спостерігалося, що зависання молекул над графеновою площиною локально змінювало їі провідність. Оцінка енергетичних затрат під час поширення молекул адсорбентів по поверхні графену продемонструвала його гідрофобність. 